\title{
Elicitation guide on parts of the body is
}

\author{
N.J. Enfield \\ Max Planck Institute for Psycholinguistics, Postbus 310, 6500 AH Nijmegen, The Netherlands
}

\begin{abstract}
This document is intended for use as an elicitation guide for the field linguist consulting with native speakers in collecting terms for parts of the body, and in the exploration of their semantics. (C) 2005 Elsevier Ltd. All rights reserved.

Keywords: Body part terms; Partonomy; Meronymy; Semantic fields; Elicitation technique; Intensional meaning; Extensional meaning; Ambiguity; Generality; Vagueness
\end{abstract}

\section{Inventory of parts}

This section concerns basic data on the way the body is semantically and referentially segmented according to the vocabulary of the language you are working on. Andersen (1978) proposes a number of universals in the semantic organisation of body part terminology, including the following:

For any language,

- there will be distinct terms for BODY, HEAD, ARM, EYES, NOSE, and MOUTH;

- FINGER and tOE are always labelled;

\footnotetext{
This is a revised version of Section 1 from Enfield (2001) (an elicitation guide titled 'Body', written for the 2001 Language and Cognition Group Field Research Manual, Max Planck Institute for Psycholinguistics, Nijmegen), updated in 2003 with input from Jürgen Bohnemeyer, Melissa Bowerman, Sotaro Kita, Stephen Levinson, Asifa Majid, Sergio Meira, Jenny Pyers, Gunter Senft, and Miriam van Staden, and revised further for publication in this special issue.

E-mail address: nick.enfield@mpi.nl
} 


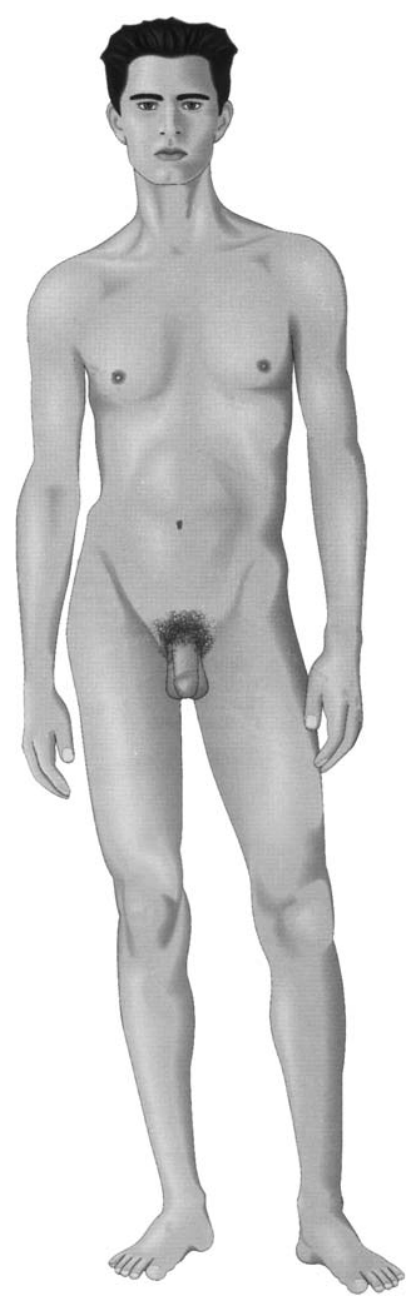

Fig. 1. Male body, front view.

- NAIL Is always labelled ${ }^{1}$;

- if there is a distinct term for FOOT, then there will be a distinct term for HAND;

- if there are terms for INDIVIDUAL TOES, then there are terms for INDIVIDUAL FINGERS;

- HEAD, TRUNK, ARM, and LEG are always 'possessed by' BODY;

- there will be a hierarchical partonomy with no more than six levels of depth.

To test these claims, first elicit as complete an inventory as possible of the terms for parts of the body in the language. Two broad formal categories of terms will be SIMPLEX

\footnotetext{
${ }^{1}$ Andersen (1978, p. 352) says that the categories FINGER and TOE are always labelled by one of 'four general patterns': (a) different terms for each (finger vs. toe), (b) one term referring to either (digit), (c) different terms sharing a common root (hand-digit vs. foot-digit), or (d) TOE derived from FINGER (finger vs. foot-finger). NAIL is always labelled by one of 'two general patterns': (a) one term referring to either (nail), (b) different terms sharing a common root (fingernail vs. toenail).
} 


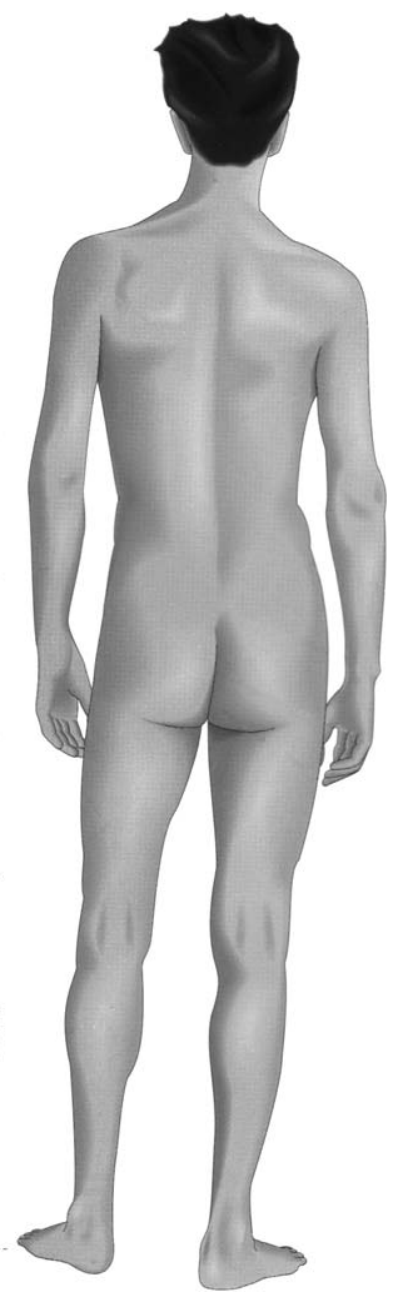

Fig. 2. Male body, back view.

(i.e., monomorphemic terms such as arm, head, knee) and COMPLEx (i.e., polymorphemic and usually semantically motivated expressions such as kneecap, fingernail, index finger). Complex terms tend not to be genuinely transparent. For instance, one of the elements may be restricted to the collocation (e.g. earlobe, eyebrow). Often a certain element will be productive in deriving multiple terms. For example, in Lao the word khoos 'joint' derives khò̀5 mùù 'wrist' (lit. 'joint hand') and khòo5 niw4 'knuckle' (lit. 'joint digit') (but not *khòo 5 khèen 3 'elbow' (lit. 'joint arm')). Be mindful of the possibility that a single body part may have a number of different labels, which differ in terms of usage (especially concerning register, politeness). For example, in Lao, references to the 'foot' are considered impolite. There are two terms for 'heel'-son2 nòng1 and son 2 tiin 3 - regarded as not impolite, and very impolite, respectively. (Cf. the very large English vocabulary for genitalia, ranging in politeness, and connotation.) There are usage effects, too. Lao speakers may avoid explicit reference to the foot, even when the foot is to be referred to. For 


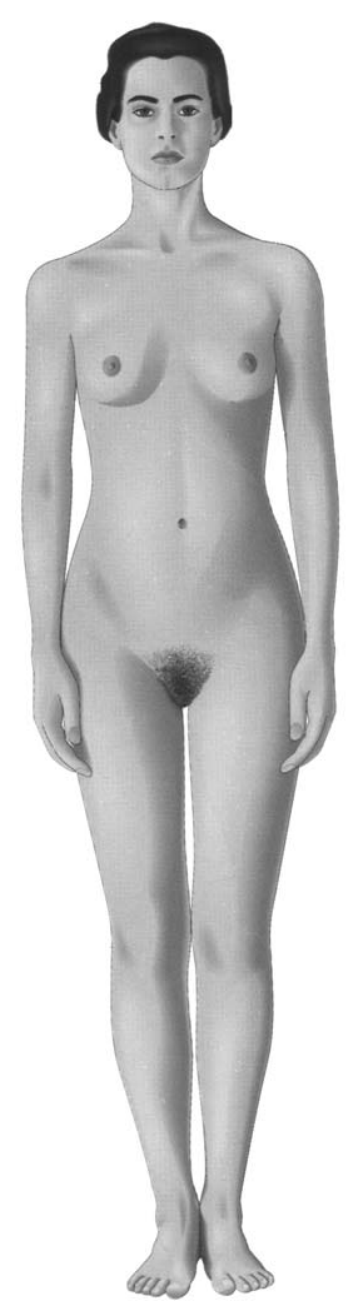

Fig. 3. Female body, front view.

example, one may say sêt1 khaa3 'wipe (your) legs' to mean 'wipe (your) feet'. Without some cultural background knowledge of the avoidance status of reference to the foot, the use of khaa3 'legs' to refer to 'feet' could be misinterpreted (i.e., one might take such a usage to mean that khaa 3 has a second encoded meaning 'foot/feet').

You may want to use illustrations as a guide in elicitation (see Figs. 1-6 and van Staden and Majid, this issue). Do not forget to elicit/explore terms for parts of the body which cannot be seen on the illustrations (e.g. 'tongue', 'teeth', 'bones', 'skin', 'heart', 'lung', 'body hair', etc.).

\section{Extensional range of body part terms}

While all languages may have words roughly equivalent to English body, head, and eye, are the precise extensions and intensions of these terms equivalent across languages? For 


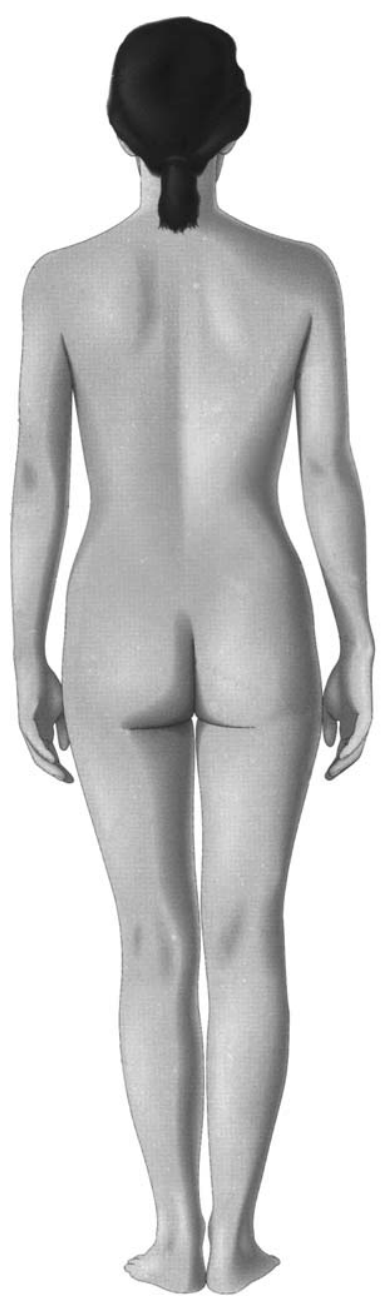

Fig. 4. Female body, back view.

example, the extensional range of English shoulder includes the joint connecting the arm to the torso, as well as areas of the arm and torso on both sides of the joint. The notion of shoulder may thus be described as 'the region of the body where the arm joins the torso'. Lao, on the other hand, has no equivalent word for 'shoulder'. The extension of English shoulder is covered by two Lao expressions: baal, referring to the horizontal region between the neck and the shoulder joint; and ngaw5 khè̀n3 (lit. 'branching base of the arm'), referring to the topmost part of the arm, from the shoulder joint down to the base of the deltoids. Thus, while English shoulder can be characterised as a region where two body parts join (thus encompassing regions of the body to either side of the joint), the Lao terms baal and ngaw5 khèen 3 cannot. Their respective extensional range is delineated at the joint itself. 


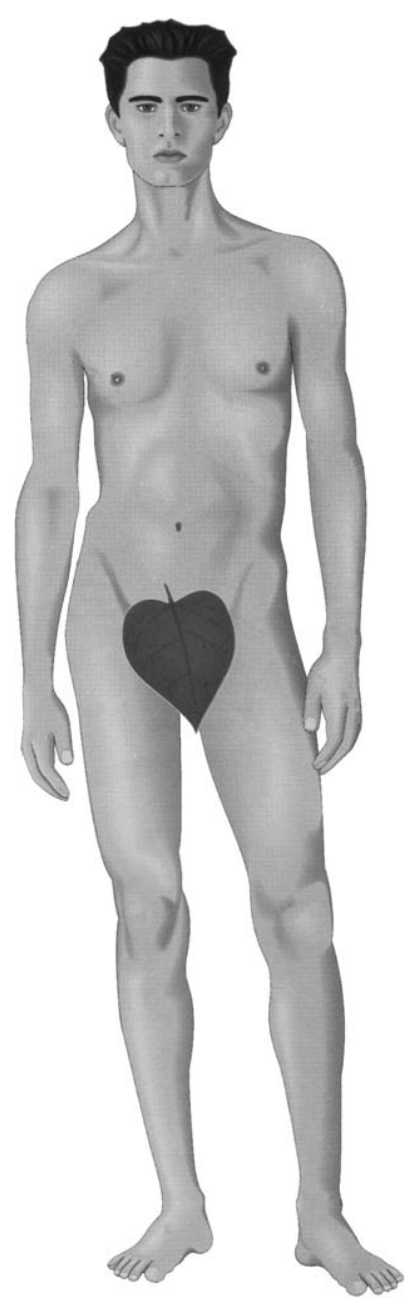

Fig. 5. Male body, front view (modest).

In order to get at the extensional range of body part terms, this elicitation guide includes six illustrations of the body, showing front and back views of men and women (including two additional 'modest' front views, in case nudity offends in your field site). With the list of terms for body parts, try to determine, as clearly as possible, the precise extensions of the terms. For example, where does 'foot' finish and 'leg' begin? There are a few ways to do this, and each of these procedures should ideally be followed with more than one consultant. Use your imagination. Here are two suggestions (see van Staden and Majid, this issue, for formal development of these):

(a) Give a pen to the consultant and ask him or her to name the various body parts, drawing outlines (i.e., not just marking points) of the specified body parts on the illustrations. 


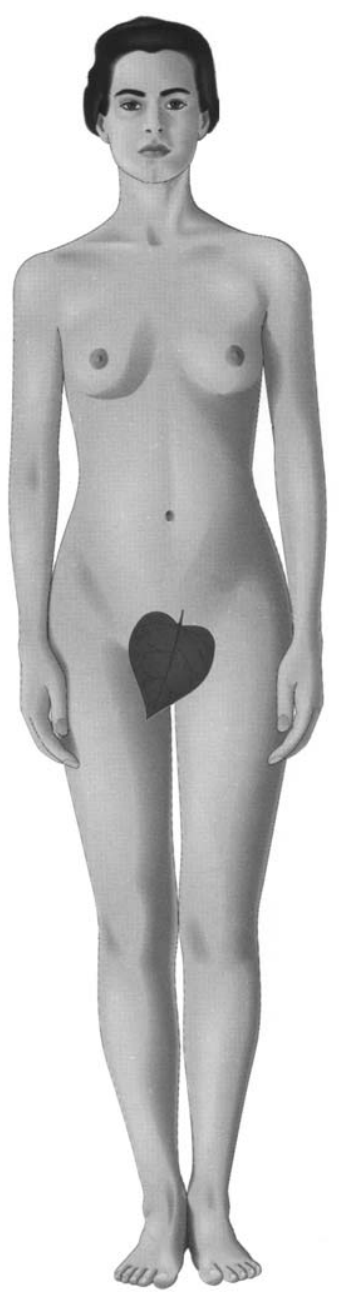

Fig. 6. Female body, front view (modest).

(b) Give a pen to the consultant. Tell him or her that 'The person has a mole/wart/birthmark/mosquito bite on his ' (supply the relevant body part term), and ask the consultant to draw it on the figure. Do this for all the main body parts.

These procedures will work for only a selection of the full set of body part terms.

\section{Intensional content of body part terms}

It is necessary to complement speakers' judgements about the extensional range of body part terms with information about what descriptive information might define the terms. Explore whether people consider terms to refer to 'areas' or 'parts' of the body. This may be established with reference to language-internal criteria. Other aspects of people's 
conceptualisation of body parts may include function (e.g. that the knee is 'part of the leg, where it bends') and position (e.g. that the head is 'above all the other parts of the body').

A possible source of relevant information concerns collocations involving body parts. For example, Lao paak5 'mouth' differs from English mouth in being used in expressions such as 'cracked mouth' to refer to what English speakers would call cracked/split/chapped lips.

\section{Ambiguity vs. generality}

Many body part terms may be used to refer to more than one body part. Of these, some are vague (i.e., semantically general), while others are ambiguous (i.e., have two different meanings). There are two kinds of ambiguity. A word is ambiguous by metonymy if two meanings of the word are related by (spatial or temporal) juxtaposition, for example if a word referred in one sense to 'lower back' and in another sense to 'upper back'. A word is ambiguous by synecdoche if two meanings of the word are related by (spatial or temporal) inclusion, for example if a word referred in one sense to 'lower back' and in another sense to 'back' (i.e., 'whole back', including lower back).

The distinction between ambiguity and vagueness is an important one, and must be established using language-internal tests. One test of ambiguity is the assertion-negation test, whereby the ability to felicitously assert and negate a single word in a single context is taken to show that the word has two distinct senses. This test shows that the English word nail is not ambiguous, due to the infelicity of ? I broke my nail, not my nail (to mean 'I broke my fingernail, not my toenail').

Another test is the I-saw-two-X's test, by which the ability to lump different referents together for the purposes of counting shows that they are referred to by the same term. Thus, the felicity of I saw two nails on the table with reference to a toenail and a fingernail demonstrates that the term nail is vague with reference to the fingernail vs. toenail distinction. The same test shows that nail is ambiguous with respect to the fingernail/toenail vs. nail-which-goes-with-hammer distinction, since I saw two nails on the table cannot refer to a woodwork nail together with a toenail.

To test whether the Khmer term dai is ambiguous (meaning either 'hand' or 'arm'), one could describe a grisly scenario in which a severed hand and a severed arm (without the hand) lay on a table. If you could say of this I saw two dai on the table, this would show that dai was vague rather than ambiguous.

If there are terms in your system which can be used to refer to more than one recognisable body part, then you need to look for language-internal argumentation (i.e., tests along the lines just described) to justify a claim of ambiguity as opposed to vagueness.

\section{Establishing 'partonomy'}

An important aspect of understanding this lexical field concerns expression of the way in which terms for parts of the body are related to terms for the body as a whole, for the person, and for other parts of the body. The language you are investigating may not have words directly translatable to English body or part, but it may have other ways of expressing the relation between two body parts, or between a body part and the body itself, as in the following English examples: 
- The arm is part of the body.

- The hand is part of the arm.

- An arm must have a hand.

- The arm and other parts of the body.

Meanings such as these may be expressed in some languages by idiomatic constructions along the following lines:

- The arm is a thing of the person.

- The arm's hand exists.

- To the leg there is a foot.

In addition, locative expressions like The nose is on the face or The neck is between the head and the torso may be useful (but it is important to keep these distinct from explicitly partonomic relations). Consider also relations of connection like The wrist joins the hand to the arm.

Language-specific expressions relating various body parts to each other are essential in providing language-internal justification for the partonomy structures with various 'levels' that Brown (1976) and Andersen (1978) suggest can be established (cf. Cruse, 1986; Chapter 7). You should be able to list the expressions in the language which can denote relation of part to whole, of locations of part X with respect to (part) $Y$, possession of part X by (part) $Y$, or connectedness between parts, and show whether and how they can be used to establish a structured and possibly hierarchical representation of the body part domain.

\section{Further points}

\subsection{Terms for 'wearing' and 'clothing'}

Schaefer (1985) raises the issue of cross-linguistic terminology for 'wearing', pointing out that the vocabulary of 'wearing' verbs as well as terms for classes of things that can be 'worn' can reveal covert distinctions in how the body is conceptually segmented (cf. Bowerman, 2005). Find out how many 'wearing' words your language has, and try to determine their distribution. (E.g. Japanese has three verbs kiru 'put on something normally placed on the upper body', kaburu 'put on something on one's head', haku 'put on something on one's feet/lower legs'; Lao has two verbs nungl 'put on something fitting on the upper body or legs' and sajl 'put on something on the feet, head, other extremities'.)

\subsection{Terms for configurational body parts}

There are special terms such as English fist and lap or Tiriyó ankapi 'peering eye' which refer not to body parts as such, but to parts of the body in certain postures. Try to find any terms such as these, and figure out as far as possible what their meanings are. Check if they are regarded as 'parts of the body' or not. For example, fist can be possessed in English (his fists), but it cannot enter into a number of other expressions which hand can (e.g.?They cut his fist off). 


\subsection{Terms for bodily emissions}

How does the language label substances from the body-e.g. 'tears', 'sweat', 'snot', 'earwax', 'sebum', 'pus', 'semen', 'milk', 'piss', 'blood', 'shit'?

\subsection{Animal body parts}

Check the extent to which terms for human body parts are used for reference to parts of animals. Check especially 'fur', 'feathers', 'beak', 'wings', 'tail'. Also, internal organs of humans and animals/birds are sometimes labelled differently.

\subsection{Body-part based measures}

To what extent are parts of the body used as measures? For example, foot, handspan, elbow ('cubit'), etc.

\section{References}

Andersen, E.S., 1978. Lexical universals of body-part terminology. In: Greenberg, J.H. (Ed.), Universals of Human Language. Stanford University Press, Stanford, pp. 335-368.

Bowerman, M., 2005. Why can't you "open" a nut or "break a cooked noodle? Learning covert object categories in action word meanings. In: Gershkoff-Stowe, L., Rakison, D. (Eds.), Building Object Categories in Developmental Time. Erlbaum, Mahwah, NJ.

Brown, C.H., 1976. General principles of human anatomical partonomy and speculations on the growth of partonomic nomenclature. American Ethnologist 3, 400-424.

Cruse, D.A., 1986. Lexical Semantics. Cambridge University Press, Cambridge.

Enfield, N.J., 2001. Body. In: Levinson, S.C., Enfield, N.J. (Eds.), Manual for the Field Season 2001. Max Planck Institute for Psycholinguistics, Nijmegen, pp. 62-76.

Schaefer, R.P., 1985. Toward universal semantic categories for human body space. Linguistics 23, 391-410. van Staden, M., Majid, A., this issue. Body colouring task. In: Majid, A., Enfield, N.J., van Staden, M. (Eds.), Parts of the Body: Cross-Linguistic Categorisation. Special Issue of Language Sciences. 